\title{
La mirada de Ortega y Gasset al teatro.
}

\author{
Ortega y Gasset's view of theater.
}

\author{
Rafael Eivan Castellano González \\ Secretaría de Cultura del Gobierno del Estado de Jalisco (MÉXICO) \\ CE: eivancast@gmail.com
}

DOI: $\underline{10.32870 / \text { sincronia.axxiv.n77.28a20 }}$

Esta obra está bajo una Licencia Creative Commons Atribución-NoComercial 4.0 Internacional

(C) $\mathrm{BY} \cdot \mathrm{NC}$

Recibido: $27 / 09 / 2019$

Revisado: $03 / 10 / 2019$

Aprobado: 22/11/2019

\section{RESUMEN}

El presente texto se cuestiona las dialécticas que existen entre el actor y el espectador para reflexionar sobre la pertinencia y la historicidad del teatro, entendido como un arte vital e inherente al ser humano. Apoyándose en las principales tesis de José Ortega y Gasset, se analiza la figura del espectador en resonancia con el juego de máscaras que proporciona la acción teatral. También se interrogan las nociones de circunstancia vital y realidad así como la importancia de estos criterios filosóficos aplicados en el teatro, todo ello estudiado bajo el prisma de las tesis perspectivistas que, si bien no buscan instalar un criterio de verdad, si invitan a pensar los discursos y las producciones que se encuentran detrás del quehacer teatral.

Palabras clave: Existencia. Espectador. Perspectiva. Vitalismo. Humanizar.

\section{ABSTRACT}

This article questions the dialectics among the actor and the public. It seeks to think about the relevancy and the historicity of the theatre and looks to understand the practice of the theatre as a vital art for the human being. Using the Jose Ortega y Gasset's principal theses about "the spectator", 
the text analyzes the game of masks installed between the actor and the spectator in the art moment but also in life. It also interrogates the notions of vital circumstance and reality and the importance of these philosophical criteria applied in theatre. II also studies the perspectivism though against the unilateral way of seeing and invites to receive the theater discourses as a gift of live.

Keywords: Existence. Spectator. Perspective. Vitalism. Humanize.

¿Cuándo somos de veras lo que somos? bien mirado no somos, nunca somos a solas sino vértigo y vacío... muecas en el espejo, horror y vómito, nunca la vida es nuestra, es de los otros, la vida no es de nadie, todos somos la vida.

(Paz, 1957, p.16.)

\section{Introducción}

Desde la vida uno se cuestiona el teatro, y desde el teatro, la vida. Pero ¿qué parte de la vida? y ¿con qué sentido? En este tiempo, después de que la historia del teatro parece haber seleccionado diversas etapas de la vida para afirmarle un sentido u otro, cada nuevo creador se posiciona desde un plano filosófico para cuestionarse ¿por qué hago lo que hago? El artista se encuentra en un estado de gracia y visualiza su obra, motivado en parte por pasión y en otra por la técnica, prepara dispositivos para hacer llegar su discurso, la expone. El espectador reacciona ante lo recibido, devuelve sus impresiones y el artista se dispone a volver a crear con lo recogido del espectador. Este sería el ciclo ideal para las compañías de teatro. Pero no siempre pasa que los temas son cercanos al espectador y a veces ni siquiera a los intérpretes. En el teatro existe el término "dar el foco" que significa resaltar o poner la atención en lo que queremos que el espectador siga. Para esto se ha estudiado desde la estructura dramática: el espacio donde se presenta, la pre-expresividad en los cuerpos, las zonas áureas... sin embargo dice Brook: "Puedo tomar cualquier espacio vacío y llamarlo un escenario - desnudo. Un hombre camina por este espacio vacío mientras otro lo observa, y esto es todo lo que se necesita para realizar un acto teatral" (1993, p.13). 
Si como dice Brook, el escenario se crea cuando un espectador observa, esto nos llevaría a pensar que el principal motivo de un creador sería poner en el escenario las inquietudes de este espectador, aunque los motores para la producción y que determinan muchas veces el discurso y la estética de la obra, suelen partir de caprichos de un mecenas que apoya a algún artista. También se da el caso que el mismo artista solvente para hacer su obra, ya sea por la obtención de recursos otorgados por el estado, por una empresa privada, donantes u otros. Si el teatro tuviera más independencia de los patrocinadores existirían más grupos independientes para crear. Martín Acosta (2016), en su conferencia magistral impartida en el Teatro Torres Bodet de Guadalajara, decía que él como director ha sido apoyado por varias becas para producir grandes pasteles y cuando no las tiene, se dedica a hacer panes. Es evidente que si los creadores fuesen los dueños totales de sus recursos habría más panaderías y más panaderos, también se harían mejores pasteles. La necesidad de expresarse sería las que llevaría a los creadores a ver y a hacer discursos teatrales más honestos. Sin embargo, y a pesar de las vicisitudes de la creación en México, el teatro que se produce en cualquier espacio arma el macrorelato del pensamiento o cultura de un pueblo; somos lo que consumimos culturalmente, pero también depende con qué fines lo consumimos, si es por entretenimiento o si es por un verdadero descubrimiento de conocimiento, para encontrar respuestas a lo real.

Cualquiera que sea el caso, el teatro es un arte complicado en donde existe codependencia, se vive a cuenta de la mirada del espectador. La labor de hacer teatro se asemeja a la de los deportes de élite, se considera a los actores unos románticos por el ideal de mantener la acción teatral, como si se tratase de un juego snob que no cualquiera tiene acceso porque implica tiempo no siempre bien remunerado, tiempo catalogado como poco útil, tiempo que parece que escasea por ser una actividad más de entretenimiento que no parece buen negocio, ya que compite contra toda una nueva cultura visual, que presenta realidades espectaculares y llega a medios masivos como puede ser el internet, el cine o la televisión. Sin embargo, el teatro con sus propias bondades mantiene su permanencia y es uno de los pocos medios donde el cuerpo del espectador y del actor son tocados al mismo tiempo, son puestos en comunión mientras dura la representación, para después volver a habitar el drama 
en lo real. Por ello el teatro que propone llegar a un lugar diferente lleva a las personas a ser diferentes, por algo es el lugar de las máscaras, donde podemos elegir ser ese otro, aunque se pierda un poco eso que somos: "Cuando te quitas la máscara... por lo menos es lo que a mí me ocurre: me entra la angustia de que una parte del rostro se queda pegada... me parece que la máscara me está arrancando también la cara" (Fo, 1998, p. 50).

La producción artística implica involucrar la experiencia e intereses de agentes alternos al creador de la obra. Quienes suelen mantener una constancia en la producción son: la formación escolar (propiamente las escuelas de arte), el teatro de autor o independiente y el teatro comercial cuyo atractivo es ser vendido como entretenimiento. En cada empresa, los patrocinadores determinan el rumbo creativo de la clase de teatro a producir.

El análisis estético y la creación actual son interesantes, se han vuelto transculturales. Hay obras que son para criticarse y otras para entretenerse, y aunque ambas puedan ser columna de un periódico, siempre tendrá más trascendencia la de sentido crítico, por eso es importante que el espectador determine en dónde desea colocar el foco de su imaginario. Esto es lo que vuelve a la obra de teatro una existencia de interrelaciones de disciplinas y agentes de la realidad. Ahora no se puede criticar una obra simplificando con la frase cómoda de "esto es teatro y esto no es teatro", así como tampoco podemos excluir a la filosofía, la semiología, la ética y la estética para su análisis; aunque cuando se mira una obra de teatro, cada quien la ve bajo su punto de vista, que es aceptable y es parte de la realidad.

Así entendido el teatro, como esta existencia que sucede en cada producción artística afirmándose como realidad en sí, es determinada como realidad por el espectador que la vive, no sólo porque la interpreta, y le da cabida en su memoria. Dos personas que vieron teatro en cualquiera de sus modalidades de producción pueden amar el teatro sin haberlo conocido igual, pero ambos conocen una idea del teatro que conduce a afirmarlo como realidad y como verdad. Esto podemos explicarlo a partir de la idea de perspectiva, que nos ofrece Ortega y Gasset.

El perspectivismo es, pues, la postura filosófica que se niega a "guillotinar al príncipe y sustituirle por el principio", ya que lo que se trata de conseguir es que ambos, príncipe y 
principio, funcionen en común armonía. Para ello es necesario asumir positivamente la tesis básica del relativismo: que la realidad es múltiple y que de ella caben múltiples perspectivas. Pero, también, hay que asumir la tesis básica del racionalismo: que la multiplicidad de los posibles puntos de vista sobre la realidad debe ser unificada desde algún principio rector. Este principio rector radica, para Ortega, en la afirmación de que esas perspectivas múltiples no son contradictorias y excluyentes unas de las otras. Muy al contrario, esas perspectivas deben ser unificadas, porque en cada una de ellas hay una gota de verdad; de modo que "la Verdad" estará constituida por la unificación de las múltiples perspectivas. Ello lleva a entender la verdad como algo que se va alcanzando paulatinamente en la medida en que se van unificando perspectivas. (Chamizo, 1998).

El actor puede comprenderse como un aprendiz de filósofo que dentro de su labor descifra al ser humano y por ello debe preguntarse: ¿quién es?, ¿de dónde viene?, ¿dónde está?, ¿cuál es su contexto, territorialidad, raza, edad?, ¿con quién se relaciona?, ¿cuáles son sus roles en la sociedad?...El actor busca seleccionar las palabras adecuadas, analiza la imagen. Cuando se trabaja un personaje, se necesita saber cuál es la necesidad primaria, los deseos, los instintos del personaje en su contexto, de ahí que la antropología ayude tanto a las humanidades como al teatro, que también estudia al ser humano en su fisonomía y su posición en el cosmos, y se preocupa de su naturaleza racional y de su espíritu, de su dimensión política y psicológica.

Siguiendo con la reflexión de Ortega y Gasset comprendemos al teatro y la labor del actor como un "acto de humanizar", pues leemos que:

Una recapacitación, hecha con tolerancia y mente abierta, invita a admitir que todo lo que existe en el entorno de cada hombre tiene valor. Valor en sentido espiritual, limpiando los intereses mezquinos. Se nota cierto vitalismo...un inefable acto de humanizar. (Urrutia, 2006, $s / p)$.

En este quehacer humanista, el actor intercambia sus pensamientos, investiga cómo se desenvuelven las relaciones, los momentos históricos y las causas que llevan a los seres humanos a crear, tener 
varias versiones sobre el origen del universo de diferentes culturas, conocer de física, sociología y metafísica. Su campo de estudio es amplio e infinito, le interesan los objetos y los significados de las máscaras.

Los temas en el teatro siempre podrán variar, el espectador un día querrá saber sobre la tragedia griega, o el origen del teatro japonés o hindú, o cómo eran los ritos para elegir a sus gobernantes, o los ritos de invocación a la lluvia o los avances de la ciencia y la conquista del espacio. La historia del teatro ya contó tragedias de dioses, elaboró viajes a la luna, obras educativas, folclóricas, clásicas, vanguardistas, de autor y por pedido al gusto del mercado, habló de las invenciones más importantes, de las insurgencias y de las instituciones. De ahí que el teatro sea un valor por sí mismo, pues se configura como una realidad en sí, verdadera en la medida en que suma las perspectivas de los espectadores. El encuentro con un discurso genera un sentimiento de vitalidad que rebasa muchas veces el pensamiento constante orientado hacia la utilidad, aunque éste no deje de mover mercadosy cuestionar los valores en turno, el espectador es cómplice de los instintos y las pasiones de los creadores. Y, eso que se muestra, que se pone en la caja negra, es lo que genera uno de los fragmentos que conforman el macro relato de un pueblo o de un continente.

Las tendencias estéticas van marcando las ideologías y surgen manifiestos que pretenden homogenizar el arte o dar un solo perfil estético, pero siempre podrá haber quien quiera salir de la norma, contar algo íntimo o simplemente hacer un espectáculo de luces y fuentes danzarinas, pero el teatro busca decirnos quién es el ser humano y refleja un tiempo que solo se puede entender viéndolo desde su contexto. Con el tiempo, aunque también van cambiando los modelos de producción, sigue manteniéndose la pregunta base como motor para la producción: ¿qué es lo que quiere ver el espectador?

Mediante la historia del arte podemos entender la forma de pensar de los seres humanos en determinada época, la eticidad de los pueblos como quería Hegel (De Zan, 2004) o lo que nos acerca a una interpretación de lo que fuimos. Si bien el terreno del filósofo es el del pensamiento y el del actor el de la acción, ambos reflexionan sobre el ser humano y sus relaciones para traducir los sentimientos y valores que operan en la historia. Una de las coincidencias entre estos dos personajes 
podría ser que el ejercicio de su disciplina los convierte en "espectadores profesionales". Tanto la filosofía como el teatro requieren de una práctica introspectiva de observación de lo humano para poder definir su objeto de estudio. Esta coincidencia la encontramos referida en la obra de José Ortega y Gasset El espectador, compilado de algunos artículos que escribe entre 1883 y 1955. En ella, el filósofo español perfila un sentido al trabajo del espectador quien es asumido como un personaje más dentro de la obra, el texto enseña a conocer la mirada del espectador. Si para escribir se tiene que aprender a leer, también debemos aprender a mirar antes de actuar, aunque también actuando se aprenda a mirar. Desde la filosofía de Ortega y Gasset, un espectador nace aprendiendo a mirar, por eso este artículo pretende ser una mirada al espectador o una reflexión desde la perspectiva del actor-espectador.

Gaspar Gómez de la Serna dice en el prólogo del libro de Ortega y Gasset El Espectador: “Ortega y Gasset invita al lector a ejercer su propia libertad de pensamiento y a contemplar la vida desde la altura de la inteligencia, practicando sin concesiones el rigor ético de la pura y ascética indagación de la verdad" (Ortega, 1971, p. 9). Así, el espectador cómplice del discurso valida con su mirada cuantas realidades le son propuestas por un emisor y les da continuidad cuando las comparte y las comenta. No hay arte que no sea político, si bien, no todo habla de la política directamente, siempre hay un posicionamiento al respecto cuando se elige entre representar una realidad $u$ otra. $Y$ aunque el actor parece negarla realidad inmediata al representar a alguien o algo más, y usar la ficción para recrear otro tiempo y otros espacios, también piensa que mediante la ficción se puede encontrar un acercamiento a la verdad. La emoción de sentir la vida del otro, la empatía que sentimos como espectadores nos permite soñarnos otros, Ortega y Gasset dice: “[...] la vida cobra sentido cuando se hace de ella aspiración a no renunciar de nada... Cuando elegimos algo, eso que seleccionamos entre una baraja de opciones nos hace dejar otras tantas maneras de ser". (Ortega, 1971, p. 28).

El actor tiene la opción de ser, en algún personaje, y toma eso que no se eligió ser para interpretarlo de manera tal que genere la empatía en el espectador, y a la vez ser, por un momento, lo que preferimos no preferir ser. Siendo así, la verdad puede caer en las redes de la utilidad. La misión del espectador de la vida y de los textos de Ortega y Gasset será entonces indagar la verdad. La verdad 
se vuelve entonces el tema del teatro, pues éste, desde el principio aristotélico de mímesis (Aristóteles, 1966, p.31), se basa en la ficción para encontrar la verdad.

La realidad que desde el principio se desveló a Ortega y Gasset fue la de la vida humana: Extraño género de realidad que consiste en un hacerse. Es en esto que el hombre se distingue de las demás criaturas, pues éstas reciben la vida y con ella, sin más, el ser: son ya todo lo que tienen que ser, mientras que el hombre debe hacerse su vida, inventársela, creársela en medio a precisas circunstancias. Por eso la vida humana es por esencia drama: el sujeto protagonista se encuentra siempre en una situación concreta, de la que percibe la realidad circunstante y de la que debe encargarse, es decir, comprenderla, haciéndola suya, absorbiéndola y liberando la razón que hay en ella: extrayendo, diré usando un lenguaje quijotesco, la razón de la sinrazón. (Martín, 2007, p.85).

Ya una vez constituidos o sabiendo quienes somos, es preciso caer en la normatividad, esto es qué tan comunes somos con los otros, o qué tan normal es lo que pasa. La psicología se encarga de una parte y la geografía de otra.

José Ortega y Gasset vivió un periodo artístico de mucho consumo y desarrollo. El principio del siglo XX le permitió estudiar el pasado postulándose desde otro lado, que si bien respeta y elogia la fuerza de sus expresiones pasadas, regresa a ver el arte por el arte. Por eso después del Cubismo, también le toca analizar el Futurismo de Marinetti. El Dadaísmo de Tristan Tzara, Man Ray, Duchamp, a los surrealistas del 1919 a 1924: Dalí, Breton, Artaud. Y en esta relación con el otro desde el arte, mira hacia el proletariado para acercarlo al arte y acabar con la burguesía, porque la intención es dar a todos la libertad de no ser útiles:

La política: Pensar utilitario. Mientras tomemos lo útil como útil, nada hay que objetar. Pero si esta preocupación por lo útil llega a constituir el hábito central de nuestra personalidad, cuando se trate de buscar lo verdadero tenderemos a confundirlo con lo útil. Y esto, hacer de la utilidad la verdad, es la definición de la mentira. El imperio de la política es, pues, el imperio de la mentira. (Ortega y Gasset, 1971, p. 28). 
Pero, si cuando el que miente sabe que miente y el otro sabe que es una mentira ¿puede llamarse falsedad? ¿O solo es mentira cuando realmente se oculta una verdad? Si el teatro es honesto será verdadero y los espectadores serían entonces unos buscadores de verdad.

Sin embargo, las ideas de cada época crean una ideología o una filosofía dominante que permea la realidad, y en el caso del idealismo se propone el conocimiento del ser y la verdad a través de imágenes como si se tratará de una puesta en escena donde van sucediendo revelaciones, todo lo mostrado va sumando al discurso de un montaje, lo que habita el presente de quien construye ese momento. Estar en el aquí y ahora es poner sobre el escenario la honestidad del actor, y lo oportuno de lo que dice, la ficción es la vitrina del pensamiento, es la caja del principito, el actor es espectador de lo que invocó y él mismo se vuelve figura u objeto de una historia más, que aunque no sea la realidad que transcribe la historia, al ser una historia nueva, es por lo tanto otra posible realidad que desnuda otras conductas de la condición humana, esas que al nombrarlas pueden doler como la tragedia, o ser siniestras o absurdas, como la comedia, lo que importa es interesar al público para diferir y dialogar.

Cuando creemos conocer todo y lo clasificamos desde el dogma dejamos de observar la realidad, como el cielo, porque siempre es igual, aunque sabemos que cambia según la temporada, no hay razón para ver cómo cambia, el cielo es cielo. Así, el mundo está lleno de cosas invisibles, que una vez localizadas las concebimos y no volteamos a mirar cómo cambian. Quienes hacen teatro desean volver la mirada a eso que vemos como cotidiano y podría ser siniestro o riesgoso. Al teatro que muestra las repercusiones de los malos hábitos o las conductas destructivas, o que se vuelve muy literal, cierto público prefiere ignorarlo. Para que el discurso comunique a la mirada del espectador se requiere la máscara o la habilidad para disfrazar el discurso para que no resulte poco interesante; las estrategias son varias y entre ellas se busca sorprender al espectador alejándonos de lo conocido. Otra estrategia es la generación de nuevas imágenes, cuando algo extraña también provoca deseo de conocerlo, lo cotidiano aburre, lo extraño despierta fascinación y si bien antes regía una sola idea del mundo y de pensamiento, ahora la diversidad de imaginarios muestra otras perspectivas de esta mímesis. 
Estas ideas se dieron a principio de siglo cuando Bertolt Brecht -dramaturgo y filósofo quien fue despojado de la nacionalidad alemana durante el nazismo, contemporáneo de Ortega y Gassetdesarrolló el concepto de Verfremdung a partir del cual desarrolla su teoría del "extrañamiento" o del "distanciamiento" (Thomson, Sacks, 1998, p.237) para mostrar la realidad resignificada. Brecht buscó conseguir mayor atención al fenómeno teatral mostrando el relieve de la necesidad humana de la felicidad como base para la vida y propuso además un teatro político para todas las áreas del Estado, no solo para las vulnerables. La propuesta fue volver a la comunión y a los discursos claros, sin prejuicios de qué es lo claro en forma y discurso.

Vivimos entre antítesis: la religión se opone a la ciencia, la virtud al placer, la sensibilidad fina y estudiada al buen vivir espontáneo, la idea a la mujer, el arte al pensamiento... Alguien al ponernos sobre el planeta ha tenido el propósito de que sea nuestro corazón una máquina de preferir. Nos pasamos la vida eligiendo entre lo uno o lo otro. ¡Un penoso destino! ¡Prolongada insistente tragedia! Sí, tragedia: porque preferir supone reconocer ambos términos sometidos a elección como bienes, como valores positivos. Y aunque elijamos lo que nos parece mejor, siempre dejamos en nuestra apetencia un hueco que debió llenarse con aquel otro bien pospuesto (Ortega y Gasset, 1971, p. 28).

Así mismo Ortega y Gasset en otro artículo publicado en El espectador, que lleva por nombre Tierras de Castilla, notas de andar y ver menciona que todo depende del punto de vista de donde se mira, de la perspectiva. Producir discursos teatrales se vuelve el oficio de retratar una realidad al servicio del que paga, los apoyos financieros apuestan a los discursos que responden a las necesidades de los problemas sociales que ellos mismos identifican como tales. Pero, sobre todo se piensa ¿a quién se le va a presentar? ¿Quién es ese espectador que validará si esto es honesto, real y vital? La respuesta la brinda posiblemente Juan Acha:

La existencia y operatividad de la crítica de arte están determinadas, al final de cuentas, por aquel sentido analítico- crítico con que la colectividad (sobre todo el grupo que crea y consume obras culturales) mira sus instituciones y valores establecidos; juzga sus costumbres y aspiraciones. (Acha, 1994, p. XVI). 
Así, un lector es siempre un espectador y hay que darse tiempo para la contemplación: Aunque el detenerse a observar no parece algo útil según Ortega y Gasset quien recurre nuevamente a Platón en su afán de defender su butaca de crítico y espectador y cita: "El mal, viene a las repúblicas, cuando no hace cada cual lo suyo" (Ortega y Gasset, 1971, p.20). En este caso es de suma importancia detenerse a observar lo que en el mundo sucede y lo que pasa en la mirada y pensamiento del que asiste a ver las propuestas de realidad sugeridas por el teatro. Tanto Brecht como Bob Wilson además de preocuparse por darle ilusión a la escena, se preguntaban: ¿desde dónde ve el espectador ese universo creado? Bob Wilson busca representar la realidad reformulando la escenografía provocando que el público realmente habite ese espacio, lo que implicaría que para montar "La Tempestad" de Shakespeare, tendríamos que inundar la sala en un primer acto (lo cual es posible) aunque con otros recursos y apelando a que también el teatro se considera un asunto de fe. Brecht con "el rompimiento", le pide al público ponerse en el contexto que la obra exige, hablándole a los espectadores, directamente a su idea del mundo. Con esto quiero decir que lo visible no sustenta que sea real. Si en el escenario se pone una vara y una tela el espectador verá eso y no imaginará que eso es un barco sino hasta que el actor la tome y se mueva como si fuera un barco para crear la convención.

Así, el teatro es tan vital para el espectador como unos anteojos, pero más que atacar a la miopía o a las cataratas, trabaja sobre los juicios. Cuando vemos un tema desde la perspectiva equivocada se puede caer en la confusión y, no ver el discurso claramente (como Otelo quien creyó en el discurso mal intencionado sobre Desdémona) tiene consecuencias drásticas. Cuando el actor crea un discurso demasiado encriptado, esto es, no pensando en su interlocutor, o ajeno a la mirada del espectador, puede resultar poco útil, se vuelve invisible para el espectador y al no ser útil, los amigos del mirar se volverán enemigos y sin ese elemento fundamental para echar a andar la maquinaria teatral (el que mira) el teatro no existe. En este sentido, las artes vivas tienen la opción de acercarse al intérprete y discutir de manera honesta los temas que generan, el teatro no es un lugar para ponerse de acuerdo sobre la verdad o la realidad. Pero, es real puesto que se habita un 
lugar en el ritual, mismo que conlleva el sentarse a observar; el cuerpo y la mente se disponen para vivir y cada espectador se lleva su parte de alegría o tristeza u otros sentimientos a casa. Por otra parte, los intérpretes tienen en general una expectativa del público al que se van a dirigir, pero el espectador se mantiene anónimo en la oscuridad. Hay una intención en el actor a la hora del espectáculo sobre cómo debiera desarrollarse el show incluso en las butacas. El actor durante la obra sondea si tiene la atención o si hay ruido en la sala, si funciona el gag o si se rieron donde no debían y en este actuar se manifiesta el tiempo y una actividad extrema, además en la vitalidad del actor puede haber tanta energía contagiosa, que podríamos hablar de la necesidad vital del arte, más que de la utilidad.

Si el consenso se da en la manipulación de la verdad, si se retoman además los temas del contexto y vamos descubriendo el orteguiano y conocido silogismo "yo soy mi circunstancia", tendríamos entonces al teatro como una fábrica de verdades o perspectivas del mundo, con muchos espectadores en la nómina de devotos para hacer del teatro una actividad libre y de identificación. Pero, esto no sucederá si la mayoría fija sus gustos y manías en las necesidades del mercado. Así, leemos en el crítico de arte Juan Acha:

La existencia y operatividad de la crítica de arte están determinadas, al final de cuentas, por aquel sentido analítico-crítico con el que la colectividad (sobre todo el grupo que crea y consume obras culturales) mira sus instituciones y valores establecidos; juzga sus costumbres y aspiraciones. (Acha, 1994, p.4).

El principal aliado del teatro es entonces el espectador. Si para mantener la industria editorial se requieren lectores, para el teatro se requiere espectadores. No se puede prescindir de la mirada del otro. A diferencia de otras artes, el espectador de teatro al igual que el actor va recreando imágenes, acompañadas de sonidos, sentimientos y recuerdos propios, que lo reintegran a su humanidad, a su condición de ser de la que ha sido desgarrada, como nos explica el filósofo del arte argentino Colombres: 
La cultura no es un lustroso adorno, sino conciencia de un ser en el mundo, de un ser -en el caso de los sectores subalternos- desgarrado por procesos de dominación que degradan en pocos años las construcciones simbólicas que fue tejiendo lentamente a lo largo de su historia, como un modo de afirmar su humanidad. (Colombres, 2009 p.22).

La experiencia teatral es un acto íntimo, pues es ahí donde se permite una mayor atención a lo que se hace entre dos seres alternos. Es algo que se construye en colectivo, (pero decantando el vocerío de la multitud, pues se eligen y seleccionan todas las voces en el silencio de lo subjetivo.) El hacer teatro es como conocer un secreto, una abreviatura de la realidad, el teatro es otro instrumento para mirar, por eso el desarrollo de la puesta en escena es como contarle a alguien más aquello que hemos descubierto; como si el teatro fuera un microscopio o una cámara que detecta cuadro por cuadro el movimiento.

La apreciación artística nos debe llevar a querer reproducir más arte, la formación de espectadores no solo debe hacer críticos sino incitar a la generación de tantos discursos, como realidades existen. Si el espectador solo es receptivo de lo que ve, sin oportunidad de replicarlo se convertirá en un público pasivo que le dará lo mismo ver una cosa que otra. Un espectador vivo es aquel que logra sumirse en el ritual que propone el teatro, un espacio de convenciones, donde nos despersonalizamos, los "Yo's" cambiando la circunstancia para digerir la realidad acotada puesta en el marco del escenario. Menciona Ortega y Gasset (1971, p.20) que todo lo que se enmarca es para resaltarlo de lo demás que lo rodea y así como un marco le da importancia a una pintura, el poder que tiene el escenario es el de potencializar lo que se ponga en él, todo gesto, todo espacio, cada color viene a ser signo, idea y por lo tanto verdad. Cuando gusta una obra, lo que hace el espectador es apropiársela, hacerla suya; la vivencia es lo que importa, la acción de estar y ser. El espectador se crea igual que el artista, se dice que un actor es uno al subirse al escenario y otro al bajarse, no solo por asumir un personaje y luego dejarlo, sino que durante el recorrido de la pieza el actor vive tal emoción que no vuelve a ser el mismo que era antes, por todo lo que la magia del teatro puede transformar. Como dato curioso, si uno tiene alguna dolencia ligera antes de actuar, en el momento 
de subir al escenario se da como un remedio inmediato, como un medicamento o un ungüento, tal curación hace que el cuerpo por un momento olvide las dolencias hasta terminar de interpretar el papel, donde el dolor puede volver y el cansancio y la energía que se derramó en el escenario vinieron a agravar el problema. Esto último está basado en comentarios informales de actores que aseguran que el teatro es medicinal, o incluso dicen que si no tienes dolencias resulta un buen placebo.

Cesar Vallejo escribió al respecto:

El artista absorbe y concatena las inquietudes sociales ambientes y las suyas propias individuales, no para devolverlas tal como las absorbió, sino para convertirlo dentro de su espíritu en otras esencias, distintas en la forma e idénticas en el fondo, a las materias primas absorbidas [...] la correspondencia entre la vida individual y social del artista y su obra, es, pues, constante ella se opera consciente o subconscientemente y aun sin que lo quiera ni se lo proponga el artista y aunque este quiera evitarlo (Vallejo, 1973. Pp.48-49).

Las herramientas para el espectáculo también son tan variables que según la astucia del creador y lo que proyecte el sujeto será tanto cuanto más revelador, sorprendente o contundente. El teatro de improvisación (y yo agregaría que el arte en general) se dice que es un lugar para despertar la espontaneidad, la sensibilidad, la fantasía, al igual que el malabar, ayuda a desarrollar el hemisferio izquierdo del cerebro. Y, pudiera parecer algo inútil, pero no lo es porque se nos acostumbra a ocultar, reprimir o aplazar nuestras inquietudes, deseos, miedos y sentimientos que sumados las comodidades tecnológicas se afecta hasta el cerebro, como la memoria. Así, hemos dejado de ser espontáneos porque: "[..] la espontaneidad es un momento de explosión, el momento libre de la expresión del individuo". (Mantovani, Cortés, Corrales, Muñoz y Pundik, 2017, pp.17-19). A pesar de ello, al crear es imposible desprenderse de las circunstancias, pero al ponerlas en juego se profanan. El juego es la rebeldía donde se ponen temas comunes y temáticas sensibles como catarsis de sentimientos de opresión, por eso es que la comedia le resulta incómoda a los que pretenden controlar el discurso hacia sus fines utilitarios. 
En efecto, cada uno es responsable por sus actos y palabras, la tendencia puede trazar vetas, pero cada quien elige el camino que le marca la circunstancia y asume sus consecuencias; para el profesional de teatro lo importante será siempre tratar de conectar con el espectador, con el otro, pero también con el espectador de sí mismo, viviendo y recordando al mundo lo que es vida y muerte. Como lo asienta Heidegger en sus momentos más lúcidos:

Con el habla puede la palabra esencial convertirse en vulgaridad, pero de todos modos es un bien, puesto que no agota el habla la posibilidad de entenderse, sino que sólo donde hay habla puede haber mundo y sólo donde hay mundo hay historia. Por lo tanto, es la garantía de que el hombre puede ser histórico" (Heidegger, 1992, p.30).

Es real. Nacemos interpretando y como los bebes, nos hacemos entender por señas y balbuceos, por naturaleza nos enseñamos a caminar, aprendemos a hablar y a defendernos. Desde la invención del fuego el ser humano pudo soñar y dejar de estar en guardia para vivir sin miedo y poder contemplar su sombra y así poder tener una libertad creadora y desarrollar la capacidad para imaginar otras posibles realidades, para inventar máscaras, explica Aristóteles: “[...] el hombre difiere precisamente de los demás animales en que es muy apto para la imitación, y es por medio de ella que adquiere sus primeros conocimientos." (Aristóteles, 1966, p.31).

En este sentido racional, el teatro tendría que pasar a conocer "la genesa" (estudio puntual y analítico de la forma) para poder recrear el mundo y elegir la parte de ese mundo que desea representar con su propuesta (lo que conocemos como eticidad) para hacer del teatro un ente en sí, para que criticar sea basado en el doble engaño de hablar desde la deshumanización para la humanización. Y para que, en esta doble mirada de la realidad, construyamos un sentido de verdad a través de los gestos y acciones; para compartir el sentimiento de sentirse vivo y tejer comunidad más allá del grupo o colectivo, para que el sentido llegue al espectador como una ceremonia; para que el escenario se confunda con el ritual. Porque, además, el escenario es un lugar influenciable, como un prólogo de la vida, que nos da una idea de que puede ser. Pero la vida siempre cambia, da pie a nuevas escenas, es ese drama de construirse, de vivir habitando un mundo de ideas, inventando o 
repitiendo historias de lo que es el presente, porque como lo dice Khalil Gibrán, todo lo que ha cambiado el mundo, fue por idea de alguien que después fue de otros tantos:

Cada belleza y cada grandeza de este mundo es creada por una sola emoción, y por un solo pensamiento en el interior del hombre. Cada cosa que vemos hoy, realizada por pasadas generaciones, fue, antes de adquirir su apariencia, antes de aparecer, un solo pensamiento en la mente de un hombre, o un solo impulso en el corazón de una mujer. Las revoluciones que han, derramado tanta sangre, y que han transformado las mentes humanas para orientarlas hacia la libertad, fueron una idea de un hombre, que vivió entre miles de hombres. (Gibrán, 2006, p.15)

Por ello, reprimir el arte independientemente de su nivel ético o estético, es como negar atención médica a un pueblo. El acceso al teatro debe ser vital para una sociedad que se precie de buscar el respeto por la libertad y de querer encontrar sus verdades, para escribir su historia. El sentido de conocerse desde todas las circunstancias implica aprender a mirarnos, saber usar la máscara de la comedia y la tragedia. El modo de abordar la máscara tiene conexión con lo que dice Ortega y Gasset: “Estar fuera de sí consiste precisamente el vivir espontáneo, el ser, y que, al entrar dentro de sí, el hombre deja de vivir y de ser y se encuentra frente a frente con el lívido espectro de sí mismo" (1971, p.46). Somos actores. Todos los días nos ponemos máscaras según la circunstancia, un día hablamos del libre mercado y otro día de la unión del trabajador. Para activar cada máscara uno tiene que observar qué expresa, encontrar la postura corporal que se adecue y una vez puesta(s) hay que tener los ojos bien abiertos. Porque a fin de cuentas la pregunta se vuelve la misma que la del escritor mexicano en su poema Piedra de Sol “La vida, ¿cuándo fue de veras nuestra?” (Paz, 1957).

\section{Referencias:}

Acosta, M. (2016). Clase magistral de dirección escénica. Conferencia en el Teatro Torres Bodet, Guadalajara, Jalisco, México.

Acha, J. (1994). Huellas Críticas. Habana, Cuba: Biblioteca Americana.

Aristóteles. (1966). Poética. Barcelona. España: Editorial Aguilar. 
Brook, P. (1993). La puerta abierta, reflexiones sobre la interpretación y el teatro. Barcelona, España: Editorial Alba.

Chamizo, P. J. (1998). José Ortega y Gasset. El perspectivismo. En Repertorio de Ensayistas y Filósofos, Universidad de Málaga, España. Recuperado de: www.ensayistas.org/filosofos/spain/ortega/ortega5.htm

Colombres, A. (2009). Nuevo Manual del Promotor Cultural. D.F. México: Conaculta.

De Zan, J. (2004). La ética, los derechos y la justicia. Argentina: Argenjus, Fores, Konrad Adenauer Stiftung. [Versión electrónica] Recuperado de: https://archivos.juridicas.unam.mx/www/bjv/libros/5/2228/1.pdf

Fo, D. (1998). Manual mínimo del actor. Hondarribia, España: Editorial Skene.

Gibrán, K. (2006) Alas Rotas. Argentina: Biblioteca Virtual Universal. https://biblioteca.org.ar/libros/130250.pdf

Heidegger, M. (1992). Arte y Poesía. D.F. México: Fondo de Cultura Económica.

Martín. F. (2007). María Zambrano. El espectador. Revista de la Asociación de Hispanismo Filosófico, 12(1). 85-92.

Mantovani, A., Cortés, B., Corrales, E., Muñoz, J. y Pundik, P. (2017). Impro 90 juegos y ejercicios de improvisación teatral. Barcelona, España: Octaedro.

Ortega, J. (1971), El Espectador. Navarra, España: Editorial Salvat.

Paz, O. (1957). Libertad bajo palabra. Obra poética 1935-1957. D.F. México: Fondo de Cultura Económica.

Thomson, P.; Sacks, G. (1998) Introducción a Brecht. Madrid, España: Ediciones Akal.

Urrutia, J. (2006). Vitalidad de la deshumanización del arte, Revista de Occidente. (300).

Vallejo, C. (1973). El Arte y la Revolución, Lima, Perú: Mosca Azul Editores. 